\title{
Digital Transformation In Indian Insurance Industry
}

\author{
${ }^{1}$ Ramesh Kumar Satuluri, ${ }^{2}$ Raavi Radhika \\ ${ }^{1}$ Research Scholar, Department of Management, GITAM University, Hyderabad \\ ${ }^{2}$ Associate Professor, Department of Management, GITAM University, Hyderabad
}

Article History: Received:11 January 2021; Accepted: 27 February 2021; Published online: 5 April 2021

\begin{abstract}
This paper titled "Digital Transformation in Indian Insurance Industry" is an attempt to give deep insights to all the readers on digital transformation in insurance space. Technological innovations are extensive and all encompassing. Disruptions are not industry specific and insurance industry is no exception to this. Recently regulator published a draft regulation on sandbox concept, which permits carriers to innovate their offering to end user. This is led by fintech and insure tech companies and carriers have structured digital boards to take this revolution forward.Major findings of this paper are usage of block chain technology and data security in insurance industry. With companies constituting digital boards, pandemic has only acted like a tailwind for the digital push wherein entire sales process is migrated to digital way of selling. This move has a multiplier effect on customer reach, cost efficiency and service precision. Customers who are keen to have the best in terms of technological innovation will be delighted with the advancement in digital transformation.Also with big data and analytics, we are coming back to risk based pricing, which is proportionate to the risk borne by the customer. This is still evolving in life insurance as the deployment of wearables is at a nascent stage.Newer technologies like AI and machine learning are facilitating companies register higher growth both on cross and upsell opportunities. This will indisputably have an immense and long term positive impact on the bottom line of most insurance companies thus enhancing profitability.Researcher concludes that digital innovation will surely have a great and positive impact on profitability of insurance companies.
\end{abstract}

KEY WORDS :Artificial Intelligence, IOT, Data Analytics, Digital, Innovations, Life Insurance, Digital Transformation,Cost

\section{INTRODUCTION}

Digital revolution is disrupting every sphere and Insurance is no exception to this. Gone were the days when customer used to walk-in to an Insurance Office to buy a policy. With the advent of smart phones, digital payments and millennial customers, nothing seems to be unfeasible. While 63\% of insurance businesses report that they are ready to move towards more digital practices, only $23 \%$ of these business are actually ready, reports a joint Forrester and Accenture study. (Insurance blog, 2017). This is because Indian insurance industry is one of the highly regulated industry across the globe. Carriers are slowly but steadily transmuting fromBrick and motor model to online operations. Policies are subscribed with a click of the button. Smart phone culture aided by Gen X \& Gen Y customers is driving this radical change. Mobile-only insurance company can be reality soon.Also made-to-order products and concise risk coverage utilizing technology are paving a way for context selling. Sachet type products with low premium and specific risk coverage are novel inventions. Customer needs are not only becoming implicit but also perplexed. Assume a prospect landing at Hyderabad Airport. GPRS tracks his/her location and pass on the lead to various carriers. Carriers set the context by researching innumerable perils prospect might confront during his stay. One of the carriers may propose a sunstroke insurance considering the temperature in Hyderabad is already hovering between 42 and 46 degree Celsius. In addition, the carrier may charge lofty premium when the policyholder is on a high way drive and minimal premium when he is in by lanes. We are close to the reality when prospect is going to command Alexa to offer the best term plan prevailing in the industry by comparing with term plans of all life carriers. Carriers have constituted digital boards and allocated budget to ascertain opportunities and areas where technology can be deployed to enhance customer service.

India is facing an unprecedented intricacy in the form of COVID, which has become a worldwide pandemic. This pandemic has a devastating impact on lives and livelihoods. Government had implemented lockdown to contain the spread but later opened up the economy as the fall in demand across sectors has had a cascading effect on the entire economy and every line of business is experiencing recessionary trends. Insurance industry is no exception to this. While Life Insurance Industry had registered a contraction of $\sim 1.17 \%$ in new business premium until January 2021(www.lifeinscouncil.org), General Insurance Industry had registered a meagre growth of 2.5\% until December 
period (www.gicouncil.in). While we had registered de-growth in Life Insurance, industry had relatively performed better vis-à-vis other industries like automobile, tourism etc. This can be credited to renewed awareness among customers on the need for financial security and the digital transformation, which companies are focusing on to survive in this turbulence. Companies constituted digital boards and investing heavily in technology. With the dawn of Artificial Intelligence and Internet and Thing (IOT), Insurance Industry is marching towards a remarkable transformation digitally without evading focus on customer centricity and a commitment to excel. Cloud based technologies will permit us to store big data without devoting multiple servers.

Newer technologies are also thrusting companies to do away with legacy applications and embrace modernization. IT Companies have confronting tasks in meeting the implicit and explicit needs of their customers. Programmers need to be innovative, futuristic and creators of disruption in digital space. Insurers to act like startups in their offerings. IRDAI initiated Sandbox committee to nurture innovations through insuretech and fintech companies, which work in alliance with insurance companies. (www.irdai.gov.in).Also considering the present situation, IRDAI has dispensed with physical signature on proposal form. Life Insurers are allowed to accept customer consent without wet signature by confirming on the link provided by insurer or validating the same through OTP (www.irdai.gov.in). There is no dearth for innovativeness since we have many foreign partners with global operations and expertise. Sandbox committee is predominantly setup to tackle these needs since amending insurance laws is quite cumbersome and entails ratification from legislature. Digital innovation is also aiding companies to build cost efficiency since most of the repetitive and redundant job is mechanized by deploying machines instead of focusing on hiring. Meanwhile IRDAI has authorized insurers to issues policies electronically during COVID times. There is no need to deliver physical policy bond and the free look period is 30 days from the date the policy is delivered through mail. (IRDAI circular August 2020).

We will examine various stages of policy life cycle and the way technology is impacting Insurance Operations. The methodology of this study is based on public disclosures, IRDA Journals and Insurance Companies websites and we had taken data pertaining to Insurance Industry.

\section{PREVIOUS STUDIES}

Previous studies have focused on studying the impact of AI and IOT on decision-making process pertaining to claims and operations.

Marcel Lotshcer and Udit Anand (2018) in their paper titled "Enabling Artificial Intelligence" opined that the LI industry would see more partnerships between carriers and insuretech companies. In addition, it is foreseeing a change in recruitment wherein more tech savvy's are recruited at various levels.

Mckinsey and Company report authored by Ramnath Balasubramanian, Ari Libarikian, and Doug McElhaney (2018), "Insurance 2030 - The impact of AI on the future of insurance", elucidated that advances in cognitive technology is a game changer. This report proposes four core elements in defining successful AI strategy viz. data capabilities, organization and talent, models and tools and change management.

Desheng DashWuaShu and HengChenbDavid L.Olsonc (2014) in their paper titled "Business intelligence in risk management: Some recent progresses", highlighted the role of data mining in enterprise risk management. They opined that analytics will aid the organizations pre-empt fraudulent transactions. It concluded that data mining techniques can be used better predict business risks.

Paolo Giudici (2018) in paper titled "Fintech Risk Management: A Research Challenge for Artificial Intelligence in Finance" elucidated that regulations across the globe have a great emphasis on risk management practices which require authenticated data across organizations. Author reiterated that big data analytics, artificial intelligence and block chain ledgers would surely address the risk management requirements of the industry.

R. Radhika and Ramesh Kumar Satuluri (2019) in their paper titled "Impact of Operating Expenses on Life Insurance Profitability in India" articulated the need to build cost efficiency in every sphere of Life Insurance operations. They opined that companies are surviving due to renewals since the new business acquisition is always a business stain. 
Few other studies were focusing on enhancing operational efficiency but there is no comprehensive research done on technological disruptions in life insurance space and the impact digital transformation is going to create on insurance profitability.

\section{ADVENT OF INSURE TECH COMPANIES}

Fintech and Insure tech companies are steering this revolution. Insurance regulator is supportive and hence came out with a discussion paper on sandbox fostering insurance companies to embrace innovation in technology by adopting use and file on products. Application seeking permission can be in any of the below mentioned areas.

- Insurance Solicitation or Distribution

- Insurance Products

- Underwriting

- Policy and Claims Servicing

- Any other

Sandbox is not a new discovery as we have countries embracing sandbox across the globe and we ae witnessing innovations that are quite different from traditional insurance

\section{POLICY LIFE STAGES}

Let us study the impact of digital revolution at various stage of Life Insurance industry.

Exhibit 1 Policy Life Stages

\subsection{DIGITAL TRANSFORMATION IN ON-BOARDING \& SALES PROCESS}

Life Insurance Industry has $\sim 24$ lakh agents across the country recruiting an average $\sim 6$-lakh agents per year. (Life Insurance Council, January 2021). Carriers are toiling on big data and analytics to outline traits of successful advisors in both Life and General Insurance. AI is playing a superior and advanced role in defining agent recruitment. Carriers with big data and years of experience are striving to comprehend the behavioral patterns of successful agents. Basis the accessible data they sketch the right profile, segment, credentials, age and the attributes which an agent need to possess. Ideal profile is outlined much in advance and suitably recruitment questionnaire is drafted and selection effected basis the score obtained on the questionnaire. Deploying AI in agent recruitment saves lots of time, as we will do away with face-to-face interviews. HDFC launched Insta PRL, which is a mobile app for on boarding of prospective agents. Two bots viz. Etty on what's app and Elley as chatbot are resolving all queries pertaining to on boarding of agents. (https://www.hdfclife.com/customer-service/service-queries).IPRU uses service assistant chatbot LiGo for service resolution and cognitive bot for query resolution. Also it deploys nudge engines to prompt for appropriate actions.( https://www.iciciprulife.com/content/dam/icicipru/aboutus/mediacentre/ICICI_Prudential_Life_Googl_\%20Assistant_Press_Release.pdf).Once the agent gets enrolled, he/she is inducted on sales process and once they acquire requisite knowledge and skill they will open business calls with prospects. In order to inculcate appropriate and desirable habits agents are rewarded with fixed pay basis the call monitoring through geo tagging. We need to be conscious to the fact that today's virtual agent is going to replace tomorrow's physical agent. AI is one-step ahead in identifying key determinants of successful agency, which will allow it to replicate high performers. Once the big data is aiding us analyze the traits of high performing agents, AI will allow us to replicate both the traits as well as training inputs to evolve them as the best.Ping An Life, an undisputed leader in technology in China has deployed AI in agent recruitment, training and enhancing productivity. (https://tech.pingan.com/en/).

Distribution training is the other area, which is being swayed by technological disruptions. Carriers have tailor-made road maps on training interventions basis vintage and designation. Most of the learning transpires through electronic/mobile learning and gamification. Complex modules are formulated using animated characters and story telling. Live webinars and on demand, training courses are accessible to every internal customer to make learning experience a comprehensive one. Verta fore, an insure tech company deploys podcast to reach their customers both internal and external. (www.vertafore.com). A podcast is an episodic series of digital audio or video files, which a user can download in order to go through the same. Raspberry Pi installed at locations and linked to server at Head Office which in executes the program and modules to preserve uniformity across locations. Virtual Training Labs integrated with LMS (Learning Management System) have multifold benefits, a facilitator can guide infinite number 
of advisors, and they will be permitted to review sessions at their own pace. Mobile learning platform permits to conduct digital quiz on products and processes to numerous users instantly and captures the inputs for analysis. Mobile learning provides a conductive platform for Senior Management Team to interact with employees in a seamless manner.E-Learning Studios have built a library of virtual reality courses to illustrate the potential of the technology in a range of circumstances and an intriguing course on improving presentational skills and public speaking. IPRU has initiated My Coach, an AI enabled training platform to train sales force on products and services. Sales team will have access to reference video, which helps them in preparing for the call before they meet the customer. My Coach has a collection of over 50000 videos since the launch. Learner's Box is the other initiative, which has in-built library of digital content with regular online test being conducted to check the understanding. (https://www.iciciprulife.com/services/download-centre.html).At Exide life, app-based training platform, My mlearning ensures that the program rolled out is the same for all employees. This will help with consistency in training irrespective of geographical location. (https://www.outlookindia.com/outlookmoney/magazine/story/futureof-insurance-distribution-in-the-new-normal-614).

Virtual meeting apps provide a congenial platform to connect to more than $100+$ users at a time providing enormous opportunity for insurance companies across to conduct training programs and customer meets digitally. With geographical barriers being knocked off, interacting with customers from diversified geographies is not unusual task. Digital meets have high patronage from users across and hence absenteeism never surfaced as core concern for these meetings. In addition, conducting presentation and seminars digitally have become a common phenomenon in the current scenario. This will authorize us to seek feedback dynamically and imparts us with a scope for analytics on student performance since it encompasses an ecosystem, which provides a cloud based training environment. In order to stem right habits, biometric is installed at select locations to capture fingerprints of agents to substantiate their presence at the branch office. Once the voluminous data is captured, it then passes on to the server for analysis. After collating records across locations AI will facilitate us build an algorithm, which will define/redefine the vital input activities for productive and successful agency. AI will also facilitate in understanding behavioral patterns of customer thus allowing us to trail close depending on gestures and body language. While we have not evolved on this area but with access to voluminous database capturing behaviors and their gestures, AI will surely help us design a program to increase sales conversions.

Carriers conceived custom-made APPs wherein the all-inclusive sales process can be concluded digitally. Digital proposal form will secure customer id, which then is connected, to pertinent server, which allows data to be downloaded on proposal form. Carrier access secured servers like Aadhaar and PAN through customer's unique id. Hence, there is no erroneous or redundant data entered by the agent. IPRU initiated automated form filling by bots, basis customer data to optimize issuance time. Customers in IPRU are allowed to upload new business documents in what's app and download all statements. . (https://www.iciciprulife.com/content/dam/icicipru/aboutus/mediacentre/ICICI_Prudential_Life_Googl_\%20Assistant_Press_Release.pdf).Aadhar linked e KYC is the other groundbreaking initiative in ascertaining the identity of customer. IRDAI permitted life and general insurers to conduct KYC through Video Based Identification Process(VBIP) and companies initiated F2F(Face to Face APPs) which is a focused approach to help sales teams in validating customer credentials at the time of customer onboarding and Video CDF feature will assist the sales team in faster login to issuance. This feature also precludes mis-selling thus boosting higher customer retention and a healthy persistency. Exide Life Insurance initiated $e$ mandate, e-standing instruction through net banking and Aadhar linked OTP authentication are aiding companies to launch all services digitally. HDFC launched Customer 360, which provides customer related interactions and multiple touch points. Insta Insure is a 3-click process to buy insurance. (https://www.financialexpress.com/money/hdfc-life-launches-instainsure-now-get-life-insuranceinstantly/1718643/).

Pacific Life (Newport Beach, Calif.) shortlisted Life.io, a Princeton, N.J.-based subsidiary of SE2 (Topeka, Kan.), to deliver an end-to-end customer origination, engagement and service experience. Life.ioGrow enables distribution partners to run a quote and needs analysis, start an application and instantly share it with a prospect, the vendor notes. Additionally, in real-time, distribution partners can have access to prospect and policy owner data and send emails, all from a single screen. (https://life.io/pacificlife-deploys-lifeio-solutionsuite/)

What's app also aids us in procuring ID and address proof instantly and the same can be uploaded in electronic sales application. Once we key-in details, we complete login process by sending a payment link to the customer. 
Customers can then select the payment mode and deposit money in insurer's account. Policies are issued instantly once the money deposited and documents submitted as per the process. In case of pendency, the same is cleared digitally through the support electronic sales application. Once the policy is issued even the bond is shared with the customer digitally. What's app along with face book are waiting for regulatory nod to sell insurance policies through what's app and face book. Both the providers are also contemplating to develop a payment portal on both the platforms, which allows customers to buy sachet or micro term plans instantly. Chat bot's are steering prospects through comprehensive financial planning by user-friendly calculators on websites superseding financial advisor face-to-face. Assessment of risk of the prospect is the most drawn-out process. With Chat bot embedding the entire process of profiling and risk evaluation, solutions can emerge digitally letting carriers refer product precisely basis the risk appetite. Customers expect comprehensive and all-inclusive solutions from insurers on risk management. Hence, insurers either need to work on multi line business or collaborate for others services viz. Home, Motor, Marine, Property and other allied services offered by General Insurers. Insurers can act as a referral point. IRDAI had approved Life Insurers to sell indemnity plans pertaining to General Insurance Companies as a combo plan. It has only to bring-in the concept of one stop solution. (www.irdai.gov.in). we may witness further integration of Life and General with technological innovation.

Digitization of sales process is near completion. Mobile wallets are into policy sourcing and offer micro term products, which are non-medical with a click of the button. They are primarily group products and are solicited instantly with KYC details. Speed and elegance is the trade secret since the expectations from customers at times are abnormal and quite demanding. Technological innovations are aiding track sales performance digitally, which is not only cost effective but also with higher standards of precision. Call status is also tracked using E-Sales through work way sheets, which captures data digitally. Application steps into analysis of conversion ratio on calls accomplished by sales person once the data is accessible. In order to augment productivity, carriers have initiated dissecting their Feet-On-Street (FOS) through geo tagging. Also previously, we could spread out to approximately 10 customers a day. Once we commence the sales process with them, we were driving efficiency on conversion. In the current scenario, we can communicate with prospects manifold thanks to social media and smart phone culture thus allowing us to work on both scalability and efficiency.

\subsection{TECHNOLOGICAL DISRUPTION IN PRODUCT PRICING \& INVESTMENT}

\section{Exhibit 2 Digital disruption}

Presently carriers charge level premium in Life Insurance basis an actuarial assumption that averages the risk of a specific age group. John Hancock, one of the oldest life insurance companies in USA proposes dynamically priced risk coverage concurring to the data available through wearables, which track diet plan, activity levels and behavioral patterns like profuse smoking and drinking (www.johnhancock.com). Customers will be enthusiastic to follow well ness programs and healthy life style since carriers incentivize them with a deduction in premium. Wearables feed-in lots of data basis, which the algorithm is built and underwriting norms initiated. Data captured from wearable provides all-inclusive picture in terms of risk evaluation and carriers will kick off gauging premium basis the health situation of the customer. Analytics would allow not only diagnosis of illness but also prognosis to study future implications. Personalized premium, which is closer to the reality, is the expectation from customer basis the application of analytics on big data.India First Life recently launched out system, which is low-code nocode sales platform. This reduces product development time by more than $60 \%$. Here the end user need not have high technical skills and great scope for innovation. (https://bfsi.economictimes.indiatimes.com/news/insurancelefficiency-productivity-and-predictability-are-mantrasbehind-analytical-models-indiafirst-life-cto/77776414).

Micro term plans is the other flavor of products. Metrics across various financial products indicate the need for more innovative solutions to target new-age customers. These products are best suited for digitally well-informed customers like sachet model in insurance. It will also fit-in the requirement of low and middle-income groups thus pushing higher penetration for insurance products. Premium cannot be predetermined basis suppositions. In fact, it has to be as proximate as it can be to the measured risk credit to algorithms in machine and deep learning. Insurance industry was away from product innovation for quite some time since it is highly regulated. Even the products designed were standard and not on real time basis irrespective of age. In addition, product designing was initiated with an assumption that there is an intermediary who will explain the benefits to customer and it is sold with face-toface interaction. Hence most of these products continue to be obsolete in the present scenario where a sale in 
enabled digitally. Product innovation has no limitations. Pay as you drive motor insurance is offered by Edelweiss General and Tata AIG General. Vehicle owners are permitted to on and off the policies whenever they want. Customers can use their mobile application to switch their policy cover on or off depending on whether they are driving or not. (https://switch.edelweissinsurance.com/).

Carriers are deploying artificial intelligence and analytics on voluminous complex data to arrive at cost of premium instead of relying on traditional statistical measurements. Leveraging telematics in auto insurance is the determinant of premium fixing. Telematics will aid in comprehending the conduct of customer while driving basis which alteration in premium is triggered.Big data and Internet of things are driving technological disruption in insurance space. Wearables feed much needed data for analysis, which allows carriers to underwrite dynamically and assess risk efficiently. Insurance companies eager to excel are investing profoundly in technology to create a value system wherein we build predictive analysis on customer browsing. Basis the browsing pattern and behavior, carriers are recommending right product for the customer. On policy, related front carriers are embracing gamification to educate customers about available options on product. This is predominantly initiated to reach out even to customers who are moderately literate and also engage them for extended hours in imparting learning or kick off knowledge transfer. Social networking sites viz. Linked Inn, twitter, face book and what's app utilized as platform to endorse products and services. Carriers connect through linked inn with their prevailing customers for renewals as well as cross sell and upsell opportunity. With digitization in all spheres touch points with customers have amplified tremendously

Fund Management is the in-house function for all carriers. Statistical functions may not be in a standpoint to forecast market drive since financial markets are never driven fundamentally and technically. Instead, they are pushed emotionally. Arithmetical functions cannot feature emotional quotient in predictive analysis. Artificial Intelligence is playing a pivotal role in fund management. Kensho is a computer system, which is broadly used across the globe by stockbrokers and investors to examine portfolio performance and foresee market volatility. It is valued as the first computer system empowered by Artificial Intelligence (www.kensho.com). Artificial Intelligence has an impactful role in investment strategy and solvency margin computation as well. With big data available on cloud, valuation of assets and liabilities, reserve calculation and solvency margin estimate can be automated and made as close as possible to the real time experience.

\subsection{DIGITAL PAYMENT OPTIONS}

\section{Exhibit 3 Payment Options}

Mobile Industry is expecting smart phone users to reach 3.8 billion by 2021(www.statista.com). Even Feature phones have the provision to pay digital through BHIM and UPI on USSD platform. Digital payments in India are expected to grow over three-folds to Rs 7,092 trillion by 2025 on account of government policies around financial inclusion and growing digitization of merchants, according to a research report. The country's digital payment market was worth around Rs 2,162 trillion in 2019-20, Red Seer Consulting said in its report.( https://redseer.com/producttag/digital-payments/). Outlook of digital payments is impelled by millennial customers who are in the era of internet obsessed with smart phone culture. With millennials swaying the buying behavior, carriers are investing profoundly on digital payment space. Carriers generate Virtual Payment Address, which will aid customers to pay their renewals with ease and convenience. Since most of the carriers operate thickly in rural areas carriers began pursuing even feature phone users and hence embraced BHIM to correspond with customer base by triggering renewal payment requests. Carriers enjoying superior presence in countryside are on a watch out for numerous payment options to settle their customers. Micro ATMs and Digital Wallets are facilitating companies disburse withdrawals, surrenders and money backs for Micro Insurance policies. Aadhar Enabled Payment Service (AEPS) is the choice, which is favored operating Micro ATMs since mainstream customers hold Aadhar card. While the present generation is obsessive about e-commerce, we also have an inexplicable phenomenon wherein mobile commerce is catching up. With mobile wallets upholding digital payments, Gen x, Gen y and even Gen z customers are enthralled with Mobile commerce. Online merchants viz. Amazon and Flipkart have already secured license from IRDA as corporate agents and we are going to witness huge disruption on the way insurance policies are sold. These carriers and Digit Insurance are in the making of products in the most uncomplicated and lucid way for the customer to comprehend. Carriers will certainly discover an immense opportunity with these online aggregators to take their mission forward. 


\subsection{ROBOTIC UNDERWRITING \& AUTOMATED CLAIM PROCESS}

Companies are attempting to digitize end-to-end process in the arena of underwriting and claims. Workflow automation has become a prerequisite and automation commenced by companies from policy login to claims status. This not only begets cost efficacy but also aid in customer centricity.

Fukoku Mutual Life Insurance Co. deployed IBM Watson to aid analyze and interpret claim data including unstructured text, images, audio and video to take a call on policy payouts.( https://www.theguardian.com/technology/2017/jan/05/japanese-company-replaces-office-workers-artificial-

intelligence-ai-fukoku-mutual-life-insurance).Liberty Mutual Insurance deployed an app to help drivers find a safe route and locate parking. It aids with quick and real-time assessment of damage to car after an accident using a smart camera with machine learning algorithm. (https://www.greencarcongress.com/2017/01/20170104solaria.html).Teambrella, a Russian Insuretech company is the first of its kind powered by Bitcoin. It uses block chain and smart contracts to execute insurance payments.( https://www.the-digital-insurer.com/dia/teambrellabitcoin-enabled-p2p-insurance/). Also with full- sized digital setup, carriers would have additional touch points with customers thus augmenting penetration and cross sell/up sell opportunity. During financial underwriting, carriers began benefitting through repositories holding financial reports viz CIBIL to assess the premium paying capacity of prospect. Automatic underwriting costs 50\% less than traditional underwriting and the same is delivered with higher standards of precision.ICICI Lombard issues $97 \%$ policies through either digital mode or paperless. It uses InstaSpect a video-based app to settle claims pertaining to motor insurance. (IRDAI Annual Report 201920).OPAL.is and WARM's Pandora platform has integrated with Underwriting Pal (UWPal), the new underwriting engine from RGAX. This platform integrates behavioral science due to which distributors and advisers are benefitted from risk assessment with higher standards of precision. This is based on how people behave than how they are assumed to behave.( https://channeleye.media/jersey-fintech-company-integrates-with-insuranceunderwriting-service/).COR is associating with life science company Bayer and One Drop, a provider of digital solutions for people living with diabetes and other chronic conditions, to create an AI-powered digital health platform to life insurance carriers and policyholders across the US. This joint effort aims to encourage customers proactively manage their health through the latest state-of-the art digital diabetes management functionality empowering policyholders to manage their chronic conditions efficiently. (https://apnews.com/press-release/prnewswire/technology-business-corporate-news-diseases-and-conditions-products-and-services-

cbd9e4e8ac5fb689d7ce4f9e367470bd).

Wearables offer lots of data basis, which the algorithm is built-in and underwriting initiated. Big data and Internet of thing (IOT) are the next big inventions in digital evolution. Wearables provide the much-needed data for analysis, which allows carriers to underwrite dynamically and assess risk on a real time basis. IOT data is both structured and unstructured. Carriers can automate unstructured data processing end-to-end using latest AI technologies like computer vision, natural language processing, fuzzy logic and machine learning. With data and built-in algorithm, carriers are into robotic underwriting without human intervention. Wearables also aid in settling claims swifter and faster since drones can be deployed to quickly capture the photos of fatal accidents and salvage once the info reaches carrier through cloud computing servers. In addition, wearables not only stow data to server but also can retrieve the same. Risk can be mitigated or avoided by cautioning a policyholder driving with increasing speed or pass into risk prone zone. Fitbit, a wearable tracks your day schedule incorporating exercise routine, food intake, weight management, sleeping patterns and all other allied activities. Axa Insurance has deployed Artificial Intelligence driven personal wellness coaching app 'Xtra', guiding users on fitness and also handles queries regarding health goals.(https://www.technologymagazine.com/company/axa-leading-innovation-hong-kongs-insurance-market)

Chabot/ Virtual Assistance empowered by Artificial intelligence are catching up with most of the millennial customers opting for it. Virtual Assistants are currently deployed to look into queries concerning customer service and claim process. What's up is utilized to share soft copy of policy bond instantly. Carriers are letting nominee upload claim documents through what is up thus initiating claim process instantaneously.Ping An Life of China has successfully deployed Artificial Intelligence in claims settlement through which $70 \%$ of the claims are paid in 30 minutes with 96\% claims covered in real time Ping An has formed an intelligence cognition technology with a combination of voice recognition and facial recognition which is applied to more than 200 scenarios. (www.pingan.cn).Lemonade Insurance company in USA combines AI and distributed ledger to process claims within one day. Bots handle 19\% of support request and the ones it cannot handle are sent to claims team. (https://www.ey.com/en_us/insurancelfive-digital-transformation-opportunities-for-insurers-post-covid-19).

Reliance Life initiatives include a digital platform, Super Express, which issues policies in a 30-minute process and provides instant customized illustration. (https://www.reliancenipponlife.com/).Agility in accessing data is 
permitting carriers to settle claims speedily and accurately.Digit insurance another insuretech company started with super simple claim process where claim can be settle through your mobile phone by uploading shooting from your phone (www.godigit.com).

Carriers are personalizing customer contact by effecting automatic speech recognition (ASR) technologies in contact centers. Voice matching technologies will register customer voice at once and identifies the same customer the moment he converse thus customizing the entire conversation. In order to enhance customer delight, carriers are seamlessly integrating technology to smoothen the process. Carriers began processing OTP transactions to make minor policy changes like partial withdrawal, nomination etc.Bajaj Allianz initiated $i$-SERV, a video based service wherein customer can avail video call service and available in five Indian languages. Customers can use this facility to make service calls. (https://www.moneycontrol.com/news/technology/bajaj-allianz-life-launches-video-callingservice-i-serv-to-enhance-customer-service-experience-4550511.html). Ackno General Insurance developed techenabled issuance policy which allows it to deliver polices with a premium as low as one rupee with high frequency and minimal cost.(IRDAI Annual Report 2019-20).

\section{ARTIFICIAL INTELLIGENCE IN FRAUD DETECTION}

Carriers can track the activities of policyholder to detect any fraudulent transaction through block chain ledger had it been approved by the regulator. Block Chain Technology will allow us to consolidate company's databases. Considering that, all claims being reported on a distributed ledger there is hardly any chance for the wrong doer to file multiple claims. All is needed for us is a unified integrated repository capturing all claim details pertaining to life carriers. With voluminous data accessible for analytics, Artificial Intelligence can be effectively deployed to build an algorithm, which can instinctively trigger an event, which falls within the definition of a fraudulent activity. Artificial Intelligence will aid us understand the pattern and behavior of fraudsters and prompt companies to act swiftly. Exceptional alerts are triggered in case of fraud risk and the analytics would assess incidence correlation. AXA, one of the top life insurance companies deployed AI fraud detection software. AXA tied up with a startup company called Darktrace to install this solution (www.infosecurityeurope.com). Once the software ascertains user pattern it begins to correlate the data in identifying a specific pattern or trend to detect fraud.

Shift Technology, which operates on fraud detection by aggregating data through various means, will notice any trend or unusual similarities in submitting claims to raise the red flag for further investigation. The algorithm will assign a score and beyond a certain threshold limit carrier will take over and investigate further (www.shifttechnology.com). Galaxy is the other startup, which programs the claim process by estimating precise damage through images submitted by claimants. Data then is analyzed with the existing database to ascertain whether the cost and accident images correspond to each other (www.galaxy.ai). Tata AIG General Insurance deploys drone technology to capture detailed videos/phots to assess the damage and uses AI/ML tools to translate captured information into deep insights.(IRDAI Annual Report 2019-20).Ping an started underwriting policies deploying Artificial Intelligence by conducting virtual interviews for health insurance. Virtual interviews are conducted for 3040 minutes by capturing body language and facial expressions, which can then be compared with the database of stored expressions to identify fraudulent intentions.

\section{VIRTUAL BRANCHES IN INSURANCE INDUSTRY}

As on 30 September'20 Life Insurance, industry has $\sim 11000$ operational branches across the country (www.lifeinsurancecouncil.com). Opening a physical branch was perceived to be the best possible way to push for higher penetration. Branches also provided the requisite eco system and office space for advisors to work on especially in agency channel. With social distancing as a norm and a reality, gone were the days when companies would be looking at footfall of distributors and walk-in customers. COVID has effectively established a work culture wherein employees of different verticals are connected digitally and trainings initiated through mobile learning and virtual classrooms viz. Zoom, Google meets. Branches with plush interior, spacious cabins to operate, meeting rooms and payment counters might disappear since branches go virtual way. With most of the payments happening online and meeting with customers initiated digitally, we will not be requiring palatial offices to perform operations. Companies only need to ensure that different verticals from sourcing to claims processing stay connected digitally through seamless integration. Many insuretech companies in general insurance space like Acko and godigit have deployed technology and started operating as virtual offices. 


\section{IMPACT OF DIGITAL TRANSFORMATION ON PROFITABILITY}

The fact remains that the end objective of insurance companies is to register higher profitability. Life Insurance Industry in India is considered as one of the least profit making industry across the globe. This is due to stringent regulatory guidelines, which direct companies to share $90 \%$ of their surplus with policyholders. The only way companies can generate enhanced profit is by reducing operating expenses. Digital innovation in all spheres of insurance operations is going to optimize cost by boosting operational efficiency. A $1 \%$ improvement in the loss ratio for a $\$ 1$ billion insurer is worth more than $\$ 7$ million on the bottom line (www.sas.com).

Let us comprehend the operating expense of insurance companies. Employee remuneration will be major pie on spending, followed by Advertisement, publicity and training. Due to the unprecedented intricacies and the impact of pandemic on unit economics, most of the companies are right sizing and giving additional responsibilities to existing employees. Also with digital connects in place viz. Zoom; Google meets etc. geographical boundaries have been erased. According to a Harvard Review report, insurance agents who embraced the digital practice reported a $65 \%$ cost reduction and a 90\% reduction in turnaround time on key insurance processes(www.hbr.org). Hierarchies were build basis centrality of operations but now with superior digital connectivity we still have employees functioning in a faraway place and catering to the needs of customers across. While we need specialists in insurance operations, digital transformation will partially affect employee cost. Also due to spike in COVID cases, most of the corporate travel have come to a grinding halt. This is also aiding in saving cost. Post COVID the other concept that had picked up strongly is establishing virtual offices. Once work from home becomes a new norm then companies can run without an office. This is going to be a huge cost saving for insurance companies. Similarly, all the other allied spending like repairs and maintenance, printing and stationery, electricity charges, administration support expenses, agents training will drastically come down with virtual offices in place. Let us assess the spending of XYZ insurance company and the contribution of expenses under various heads. Also with digital transformation in place, we need to evaluate the savings derived by insurance companies. We have few costs, which are fully written off by digitization, and others, which have a partial impact. From the cost segregation mentioned below, it is pertinent that Employee remuneration and administration expenses form the major share. While employee remuneration and labor cost is partially influenced by digital evolution due to integration of homogenous functions, companies would enjoy high savings in other expense heads. Using technology acko insurance is in a position to bring down cost and offer close to $80 \%$ discount on two wheeler and four-wheeler insurance. It advertises 2 minutes policy buying experience (www.acko.com).

Exhibit 4 Breakup of Operating Expenses

When we analyze the overall operating expense of insurance companies, it is pertinent to note that digital transformation has positive impact on $93 \%$ of the total cost. This has prompted companies to float digital boards and build digital roadmaps.

\section{RESULTS AND CONCLUSION}

With the mobile phone users reaching 500.9 million by 2023, digital payments and M commerce are going to sway insurance carriers (https://www.statista.com/statistics/558610/number-of-mobile-internet-user-in-india/).As per the report submitted by Internet society a mobile network covers $94 \%$ of the global population, $48 \%$ are covered by mobile broadband and $28 \%$ have subscribed to mobile internet services (www.internetsociety.org).

This is phenomenal considering the data utilization and availability of feature phones in rural areas. Ecommerce portals and mobile wallet providers have commenced their operations as corporate agents and started offering customized micro term non-medical plans to capture the growing digital market. With this inevitable change in the offing, we are going to live through a disruption in life insurance space. In addition, the task of Online Portals and Web Aggregators cannot be undermined considering their reach and technological innovations, which they deploy in sales process. With big data in place obtained through IOTs (Internet of Things) and various servers, there is enough and further scope for analytics and employing artificial intelligence. However to take this forward government need to seriously work on implementing robust cyber security laws enacted by parliament. One of the main reasons why we do not notice greater access on digital front is the trust factor. Most of the users are apprehensive about data 
confidentiality and the means to validate the transaction. We need to have a strong cyber security law enacted by parliament, which addresses these concerns.

Block Chain technology has multi fold benefit to Life Insurance Industry. Once we have a shared ledger, all the time consuming activities like KYC verification, Claims process can be processed automatically. In addition, we can have access to all-inclusive information like credit history reports, medical tests, hospitalization details, medications used, previous policy details and claim information. However, as of now regulator has not given formal approval to the usage of block chain technology since it is subjected to legal scrutiny and other confidentiality issues. Hence, we cannot benefit out of this technology.Recently AP Govt. utilized block chain technology for e-governance and has uploaded all the land records. The aim of the project is to minimize tampering of land records, which are digitized and available online. (https://economictimes.indiatimes.com/small-biz/security-tech/technology/blockchain-tech-isjoining-e-gov-dots-in-ap-telangana/articleshow/59330625.cms?from $=m d r$ )

Data security is the vital issue to be addressed with a spike in online transactions/payments. User authentication process needs a makeover. It is time that we have multi-layered structure to authenticate digital transactions so that we do not anticipate any fraudulent transactions. Carriers may not have a role to play in Digital Payment gateways. However, they are accountable for safeguarding voluminous customer base since they have a fiduciary relationship. Cyber security regulation stipulates very little clarity on data protection. They naively mandate privacy of customer data without prescribing any measures for data protection and prevention of exploitation of such data by unknown entities. 'Let us chat insurance,' prompts the chatbot of an emerging insurtech, offering bite-sized, customized insurance plans. The question is whether insure tech companies compromising on data security.

With big data and analytics, we are coming back to risk based pricing, which is proportionate to the risk borne by the customer. Analytics provide us unprecedented insights about customer health, behavior and overall profile. Untilnow, carriers are designing products based on average pricing basis the age band. This pricing gives enough cushions for insurers in the initial years where they will build a surplus. This may not be possible with risk-based premium where the premium charged is precisely equivalent to the risk borne by the customer. Customers are demanding hence carries need to offer value added services thus leading to customer delight. Since companies are going to charge risk based premium it is imperative that we guide customers with well ness programs, pre-medical check-ups and concessional treatment from select hospitals/diagnostic centers.

\section{REFERENCES}

\subsection{JOURNAL ARTICLE}

1. DeshengDashWuaShu., HengChenbDavid., L.Olsonc. (2014). Business intelligence in risk management: Some recent progresses: Sciences, Volume, 1-7.

2. Paolo, Giudici. (2018). Fintech Risk Management. A Research Challenge for Artificial Intelligence in Finance: frontiers in artificial intelligence, 1-6, Volume 204, Issue 2, 189-198.

3. R. Radhika., Ramesh Kumar Satuluri (2019). Impact of Operating Expenses on Life Insurance Profitability in India: International Journal of Human Resource Management and Research(IJHRMR), Volume 9 Issue 1, 53-60

4. IRDAI Annual Report (2019-20).RESEARCH AND DEVELOPMENT ACTIVITIES UNDERTAKEN BY THE INSURERS, 34-40

\subsection{ARTICLE FROM THE WEB}

1. J.F. Gasc. (2015). Are Insurance Companies Getting Enough Bang from Their Digital Investments Buck? Retrieved from http://insuranceblog.accenture.com/are-insurers-getting-enough-bang-from-their-digitalinvestments-buck/

2. Industry Performance (2020).Segment wise report December 2020. Retrieved from https://www.gicouncil.in/statistics/industry-statistics/segment-wise-report-on-homepage/

3. IRDAI Circular(2020). Issuance of Electronic Policies. Retrieved fromhttps://www.irdai.gov.in/ADMINCMS/cms/whatsNew_Layout.aspx?page=PageNo4208\&flag=1

4. The Magazine (2018). Enabling Artificial Intelligence in Life Insurance. Retrieved from https://themagazine.synpulse.com/en/2018_07_13_enabling-artificial-intelligence-in-life-insurance/ 
5. HDFC Life Service-queries (2020). Onboarding of agents through bots. Retrieved from https://www.hdfclife.com/customer-service/service-queries

6. Financial Express(2019). HDFC Life launches InstaInsure; now get life insurance instantly. Retrieved from https://www.financialexpress.com/money/hdfc-life-launches-instainsure-now-get-life-insuranceinstantly/1718643/

7. ICICI Prudential Life Media Centre (2020).ICICI Prudential Life Launches AI-powered voice chatbot on Google Assistant.Retrieved from https://www.iciciprulife.com/content/dam/icicipru/aboutus/mediacentre/ICICI_Prudential_Life_Googl_\%20Assistant_Press_Release.pdf)

8. ICICI Prudential Life download (2020). My Coach and Learner's Box. Retrieved from https://www.iciciprulife.com/services/download-centre.html

9. BHATIA, K. Library \& Information Officer, National Institute of Occupational Health, Meghaninagar, Ahmadabad, India.

10. Economic Times(2020).Efficiency, productivity and predictability are mantras behind analytical models: India First Life CTO. Retrieved fromhttps://bfsi.economictimes.indiatimes.com/news/insurance/efficiencyproductivity-and-predictability-are-mantras-behind-analytical-models-indiafirst-life-cto/77776414

11. Switch.edelweissinsurance(2020).Edelweiss SWITCH - Driver Based Insurance. Retrieved from https://switch.edelweissinsurance.com/

12. Digital Initiative (2019).Kensho - made in the Square, trades on the Street.Retrieved from https://digital.hbs.edu/platform-digit/submission/kensho-made-in-the-square-trades-on-the-street/

13. Iqbal, P. M., \& Baba, A. M. (2016).Currency of Research Articles for Select Major Search Engines in the Field of Library \& Information Science. IASET: International Journal of Library \& Educational Science (IASET: IJLED), 2(2), 61-70.

14. Redseer (2020).Indian Mobile Payments: $5 x$ growth by 2025.Retrieved from https://redseer.com/producttag/digital-payments/

15. The Guardian(2017).Japanese company replaces office workers with artificial intelligence. Retrieved fromhttps://www.theguardian.com/technology/2017/jan/05/japanese-company-replaces-office-workersartificial-intelligence-ai-fukoku-mutual-life-insurance

16. Green Car Congress(2017).Liberty Mutual Insurance's Solaria Labs unveils new developer portal for future products and apps; from safest routing to damage assessment. Retrieved fromhttps://www.greencarcongress.com/2017/01/20170104-solaria.html

17. The Digital Insurer (2020).TeambrellaBitcoin Enabled p2p Insurance. Retrieved from https://www.thedigital-insurer.com/dia/teambrella-bitcoin-enabled-p2p-insurance/

18. Vanan, C. K., \&Subramani, R. (2015). Digital divide: rural and urban college students 'attitude towards technology acceptance. International Journal of Communication and Media Studies (IJCMS), 5(4), 1-8.

19. CHANNEL EYE (2021). Jersey Fintech Company integrates with insurance underwriting service. Retrieved fromhttps://channeleye.media/jersey-fintech-company-integrates-with-insurance-underwritingservice/

20. Apnews.com(2021).One Drop to Work with SCOR and Bayer on Life Insurance Products for People with Chronic Conditions.Retrieved from https://apnews.com/press-release/pr-newswire/technology-businesscorporate-news-diseases-and-conditions-products-and-services-cbd9e4e8ac5fb689d7ce4f9e367470bd)

21. SARDAR, K., \& PATIL, R. DIGITAL MANUFACTURING OF DENTAL IMPLANTS USING COMPUTER AIDED ENGINEERING AND FUSED DEPOSITION METHOD.

22. Technology Magazine(2020).AXA: Leading innovation in Hong Kong's insurance market. Retrieved from(https://www.technologymagazine.com/company/axa-leading-innovation-hong-kongs-insurancemarket)

23. Ey.com (2021).Five digital transformation opportunities for insurers post COVID-19.Retrieved from https://www.ey.com/en_us/insurance/five-digital-transformation-opportunities-for-insurers-post-covid-19

24. Agnihotri, D., \&Chaturvedi, P. (2015). A Study on Customer Preference and Attitude Towards Major Efloors with Special Reference to Kanpur. BEST: International Journal of Management, Information Technology and Engineering (BEST: IJMITE), 3(12), 21-28.

25. Reliancenipponlife.com(2020).Digital platform Super Express to issue policies instantly. Retrieved from https://www.reliancenipponlife.com/

26. Godigit.com (2019).Digit Insurance Claims Report Card. Retrieved from https://www.godigit.com/blog/digit-claims-report-card

27. Info security (2015).The Politics of Cybersecurity. Retrieved from https://www.infosecuritymagazine.com/digital-editions/q2-2015-volume-12-issue-2/ 
28. Moneycontrol.com (2019).Bajaj Allianz Life launches video calling service 'i-SERV' to enhance customer service experience.Retrieved fromhttps://www.moneycontrol.com/news/technology/bajaj-allianz-lifelaunches-video-calling-service-i-serv-to-enhance-customer-service-experience-4550511.html

29. Shift-technology.com(2020). Shift detects fraud with twice the accuracy of other solutions. Retrieved from https://www.shift-technology.com/shift-claims-fraud-detection/

30. Galaxy.ai (2019).Rising Auto-Insurance Claims Costs. Retrieved fromhttps://www.galaxy.ai/claims

31. AGRAWAL, E., \& MANU, K. INTERCHIP INTERCONNECTIONS.

32. Lifeinscouncil.org (2020).The Life Insurance Industry in India.Retrieved from https://www.lifeinscouncil.org/About/IndustryOverview

33. Sas.com (2020). 6 ways big data analytics can improve insurance claims data processing.Retrieved from https://www.sas.com/en_in/insights/articles/risk-fraud/big-data-analytics-improves-claims-processing.html

34. Harvard Business Review (2014). Insurance Companies' Untapped Digital Opportunity. Retrieved from https://hbr.org/2014/03/insurance-companies-untapped-digital-opportunity

35. Statistica.com (2020).Mobile phone internet users in India 2015-2023.Retrieved from https://www.statista.com/statistics/558610/number-of-mobile-internet-user-in-india/

36. Economictimes.com (2017).Block chain tech is joining e-gov dots in AP, Telangana. Retrieved from https://economictimes.indiatimes.com/small-biz/security-tech/technology/blockchain-tech-is-joining-e-govdots-in-ap-telangana/articleshow/59330625.cms?from=mdr)

$\begin{array}{llll}\text { 37. Iciciprudential.com (2021).Business Presentation. } & \text { Retrieved }\end{array}$ https://www.iciciprulife.com/content/dam/icicipru/about-us/investor awareness/Business_Presentation_Update.pdf

38. Hdfclife.com (2020).Investor Presentation. Retrieved from https://brandsitestatic.hdfclife.com/media/documents/apps/HDFC\%20Life\%20Presentation\%20\%20Q1\%20FY21\%20Final.pdf

39. Internet Society's Global Internet Report (2015).Mobile is Key to Fulfilling the Promise of Internet Connectivity for the Next Billion People (2015 GIR) 7 July 2015. Retrieved from https://www.internetsociety.org/history/2015/internet-societys-2015-global-internet-report-mobile-is-keyto-fulfilling-the-promise-of-internet-connectivity-for-the-next-billion-people-2015 gir/\#: :text=Focused $\% 20$ on $\% 20$ the $\% 20$ impact $\% 20$ of,the $\% 20$ Internet $\% 20$ through $\% 20$ mobile $\% 20$ devices.

40. Acko.com (2020).Two Wheeler Insurance. Retrivedfrom https://www.acko.com/two-wheeler-insurance/

41. Pingan.com (2020).Intelligent Cognition. Retrieved from https://tech.pingan.com/en/

42. Johnhancock.com (2020).John Hancock Vitality Life Insurance that rewards healthy living. Retrieved from https://www.johnhancock.com/life-insurance/vitality.html

43. Irdai.gov.in (2021).REPORT OF THE EXPERT COMMITTEE ON HEALTH INSURANCE. Retrieved fromhttps://www.irdai.gov.in/ADMINCMS/cms/Uploadedfiles/health_report\%20220515.pdf

44. Vertafore.com (2020).The future of Insurance with Bryan Falchuk. Retrieved from https://www.vertafore.com/resources/podcast/future-insurance-bryan-falchuk

45. Asia Advisers Network (2019).Innovation at Ping An and the Next Wave of insurance - EY Global Insurance Knowledge Leader. Retrieved from https://www.asiaadvisersnetwork.com/Article?aid=49360

46. Lifeinscouncil.org (2021).New Business Performance of Life Insurance Companies. Retrieved from https://www.lifeinscouncil.org/industry\%20information/NewBusinessPerformance

47. Irdai.gov.in (2021).IRDAI Regulatory Sandbox. Retrieved from https://www.irdai.gov.in/ADMINCMS/cms/frmGeneral_Layout.aspx?page=PageNo3880

48. Irdai.gov.in (2021).Dispensing with physical signature on proposal forms. Retrieved fromhttps://www.irdai.gov.in/ADMINCMS/cms/whatsNew_Layout.aspx?page=PageNo4210\&flag=1

49. Irdai.gov.in (2021).Life Insurance Agents Data. Retrieved from https://www.lifeinscouncil.org/industry\%20information/IndividualAgentsData

50. RamnathBalasubramanyam, Ari Libarikian, and Doug McElhaney.(2018, May).Insurance 2030- The impact of AI on the future of insurance (Web log post). Retrieved July 1, 2019, from http://www.mckinsey.com

51. Outlookindia.com (2020).Future of Insurance Distribution in the New Normal. Retrieved from https://www.outlookindia.com/outlookmoney/magazine/story/future-of-insurance-distribution-in-the-newnormal-614

52. iireporter.com (2021).Pacific Life Deploys Life.io to Transform Digital Customer Experience. Retrieved from https://iireporter.com/pacific-life-deploys-life-io-to-transform-digital-customer-experience/ 


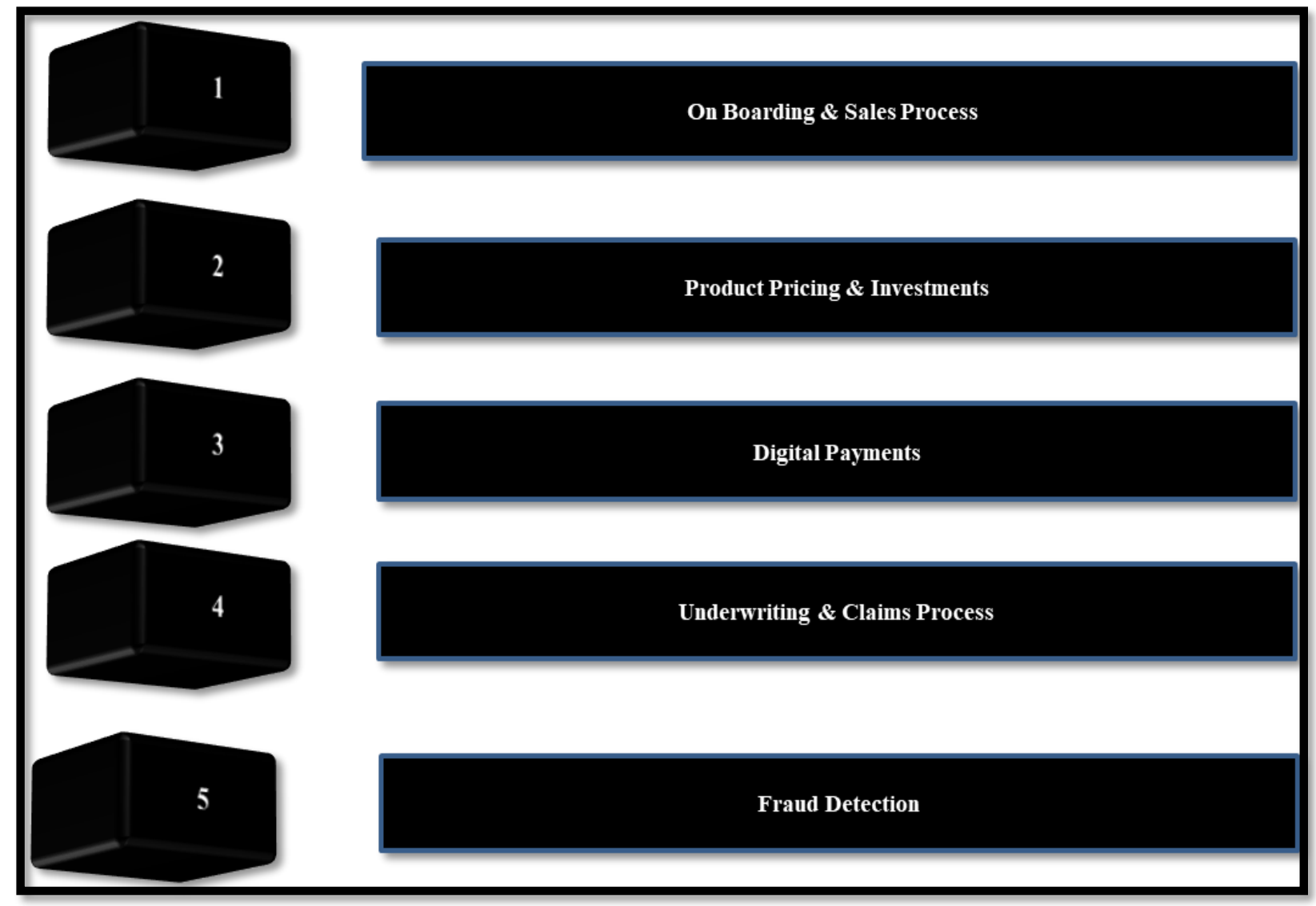

Exhibit 1 Policy Life Stages

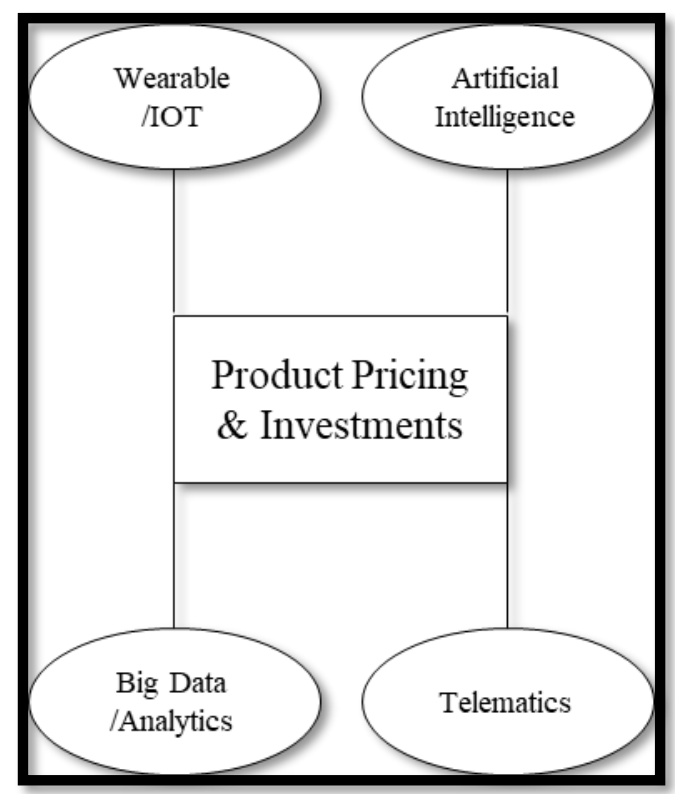


Exhibit 2 Digital disruption

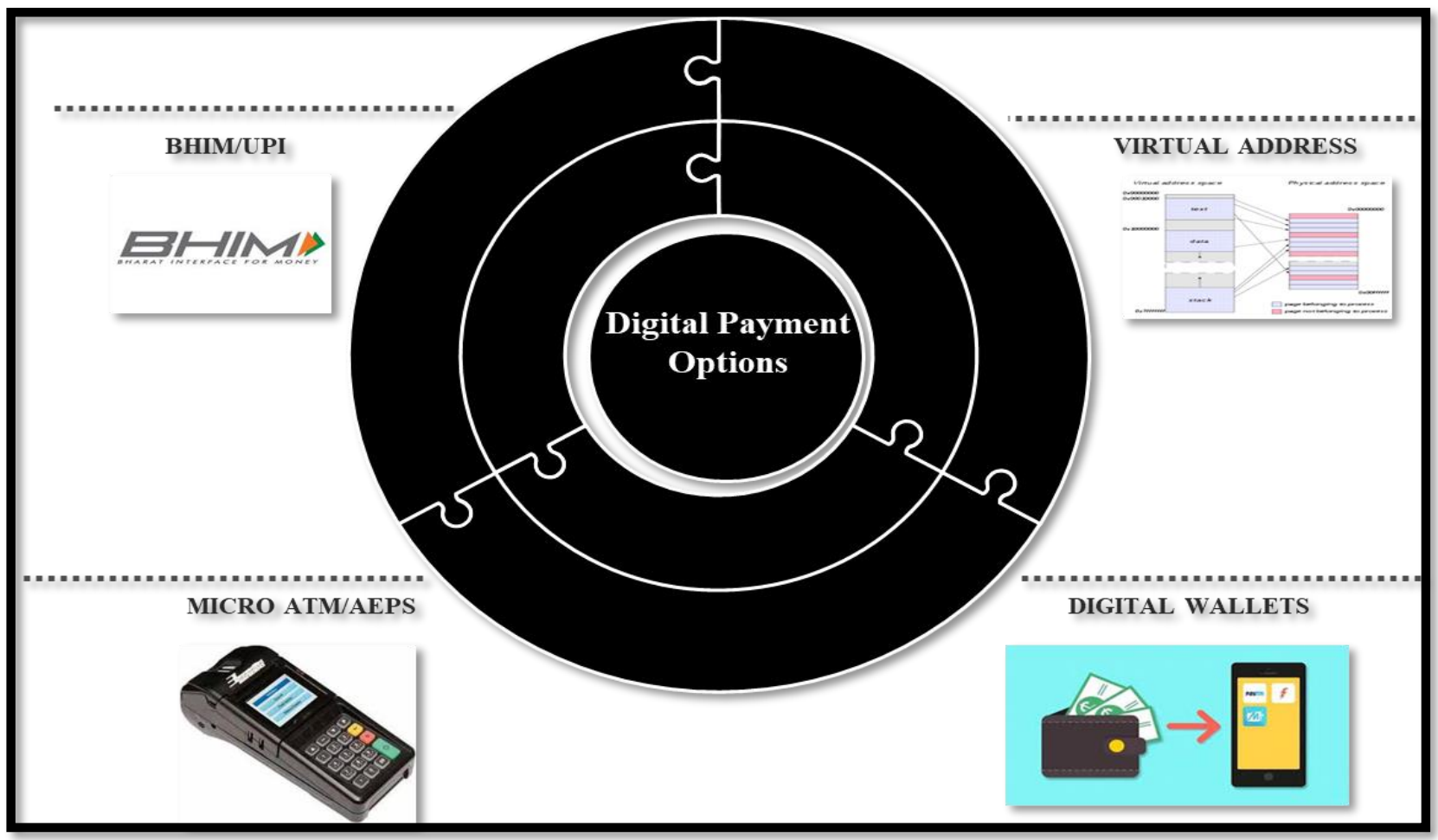

Exhibit 3 Payment Options

\begin{tabular}{|c|c|c|}
\hline Break up of Operating Expense & \% Share & $\begin{array}{c}\text { Will digital } \\
\text { transformation save cost? }\end{array}$ \\
\hline Employees' remuneration and other manpower costs & 35.65 & Partially \\
\hline Travel, conveyance and vehicle running expenses & 1.93 & Fully \\
\hline Rent, rates and taxes & 4.56 & Fully \\
\hline Repairs, maintenance and office upkeep & 1.41 & Fully \\
\hline Printing and stationery & 0.20 & Fully \\
\hline Communication expenses & 3.47 & Partially \\
\hline Legal expenses & 1.94 & No \\
\hline Medical fees & 0.69 & No \\
\hline Advertisement and publicity & 8.67 & Partially \\
\hline Interest and bank charges & 0.67 & No \\
\hline Agents training (Training expenses) & 7.68 & Fully \\
\hline Recruitment expenses & 0.20 & Fully \\
\hline Electricity, Water \& Utility Charges & 0.21 & Fully \\
\hline Sales and business promotion expenses & 0.20 & Fully \\
\hline
\end{tabular}




\begin{tabular}{|c|c|c|} 
Depreciation & 2.57 & No \\
\hline Information technology cost & 2.90 & Partially \\
\hline Administration support expenses & 25.87 & Fully \\
\hline Security and housekeeping & 0.20 & Fully \\
\hline Distribution expenses & 0.22 & Partially \\
\hline Data entry related expenses & 0.75 & No \\
\hline Total Opex & $\mathbf{1 0 0 . 0 0}$ & \\
\hline
\end{tabular}

Exhibit 4.0 Operating Expense

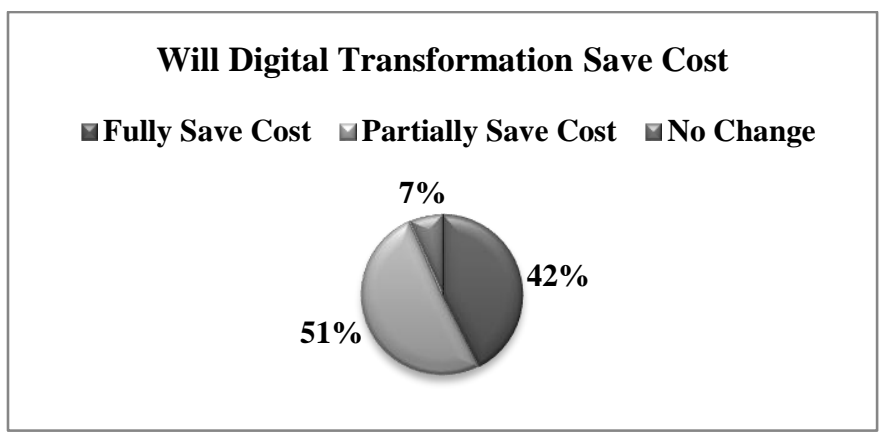

Exhibit 4.1 Cost Saving

\section{Biographical Note}

Ramesh Satuluri has 25+ years of experience in corporate and has sound knowledge in sales, marketing, people management, customer service training and agency building. Presently he is working as General Manager-Sales Training with Exide Life Insurance Company Limited. On Professional front he is a CFP from FPSB, Fellow from Insurance Institute of India, Associate from Life Office Management Association, MFA from LIMRA, Master Trainer from KBI on PPE/TAP model and AMFI certified from NSEIT. As per his academic qualifications, he is a Commerce and Law graduate. He has completed his MBA and MPhil and currently pursuing PHD in Finance. He contributed many articles in various national and international magazines on finance and insurance related matters. He can be reached on Ramesh.satuluri@exidelife.in

Dr.Raavi Radhika has 26 years of experience in teaching Advanced Management Accounting, Costing Accounting, International Financial Management, Investment Management, Business Law, Strategic Management Accounting, Advanced Corporate Accounting, Financial Services, Income Tax. She has been awarded PhD from Osmania University in finance her thesis on "Lending by Co-Operative Banks to Priority Sector in Ranga Reddy Dist". 